\title{
Visual influence on taste sensitivity
}

\author{
DONALD G. JAMIESON \\ The University of Calgary, Calgary, Alberta T2N IN4, Canada
}

\begin{abstract}
A claimed dependence of taste sensitivity on body state, accepted for 40 years, is investigated in two experiments. Neither the growth of sensation above threshold, as measured in a magnitude estimation experiment, nor taste sensitivity near threshold, as measured by a signal detection analysis, show the claimed increment when individuals are dark-adapted. On the contrary, in both cases, performance is superior in the light, when subjects taste with their eyes open, possibly due to an arousing effect of concurrent visual stimulation.
\end{abstract}

In 1939, the Russian investigator Dobrjakova reported that subjects who were dark-adapted demonstrated enhanced sensitivity to (electric) taste. While no replication of this result ever appeared, and although the result was confined to electrically induced taste, it is interesting from a contemporary viewpoint (for example, at least in Canadian restaurants, food quality seems inversely related to illumination level). Moreover, the result is potentially understandable in evolutionary terms: The electric taste studied by Dobrjakova is commonly reported as sour (cf. Bujaz, 1971), and sour or bitter tastes are common correlates of poisonous materials (cf. Nachman \& Cole, 1971). Thus, it may not be unreasonable to expect that a special system of sensitivity to these tastes would have been selectively favored by survival rates. This system would be especially important when the individual was unsure of the precise nature of the food ingested, as when the food was new or when it was being consumed in the absence of identifying visual cues, as in the dark. Thus, sensitivity to potentially dangerous tastes could well improve in the dark, since it would have increased survival rates for our ancestors. In addition to the possibility that the darkadapted body state is associated with greater taste sensitivity, there is a second possibility-that attention to taste might be better focused in the dark, since competing visual stimuli would be absent. In fact, in personal communication, this explanation of Dobrjakova's result is the one most commonly volunteered by psychologists, and it echoes the claims of numerous audiophiles, lovers, and gourmets, although it has been denied empirical support (e.g., Ozbaydar, 1961).

The present experiments oppose these two notions of attention and (body) state-dependent sensitivity by testing subjects (1) when they are dark-adapted and

This work was supported by a grant from the Natural Sciences and Engineering Research Council. I am grateful to Steven Westby for assistance with data collection and analysis. Reprints are available from the author at the Department of Psychology, University of Calgary, 2500 University Drive N.W., Calgary, Alberta T2N 1N4, Canada.
(2) when they are not dark-adapted but close their eyes prior to and during each judgment. A third condition, testing in the light with eyes open, is included as an important control, since most of the available work on sensory interaction predicts visual stimulation to have an arousing effect-to enhance sensitivitycontrary to Dobrjakova's result and to numerous intuitions.

\section{EXPERIMENT 1}

\section{Method}

Stimuli. Nine test solutions of $\mathrm{CH}_{3} \mathrm{COOH}$ (acetic acid), in concentrations of $.001, .003, .007, .01, .03, .07, .1, .3$, and $.7 \mathrm{M}$, were used in all sessions. Subjects tasted each solution five times per session with solutions presented in five randomized blocks of nine trials. Solutions were tasted from 3-oz waxed paper cups, immediately af ter pouring. Stimuli and rinse were held at $23^{\circ} \mathrm{C}$.

Procedure. At the beginning of Session 1, each of the nine subjecis tasted the weakest $(.001 \mathrm{M})$, standard $(.03 \mathrm{M})$, and strongest $(.7 \mathrm{M})$ solutions to gain knowledge of the range of concentrations to be presented. Beyond the range of concentrations to be tasted, subjects were given no information about the structure of the tasting sequence. Standard magnitude estimation instructions were then given (cf. Marks, 1974), and the subjects were told that the taste of the standard solution was to be called 10 , with numbers assigned to weaker and stronger solutions to reflect the ratio of their taste to the standard.

After several tastes of the standard solution, the subjects proceeded to the first block of nine solutions, rinsing with distilled water before each taste. The subjects again tasted the standard solution before each of the $2 \mathrm{nd}, 3 \mathrm{rd}, 4 \mathrm{th}$, and 5th blocks of nine trials. Within each block, each of the nine concentrations was presented exactly once, in a randomized order. Responses for each trial were handwritten by subjects on an index card.

The subjects were tested once in each of three light conditions: eyes open, eyes closed, and dark-adapted. In the eyes-open condition, the subjects were tested under the normal fluorescent lighting in the laboratory (cool white, of intensity $483 \mathrm{~lx}$ at the subject's eye level). The eyes-closed condition differed from the eyes-open only in that the subjects closed their eyes before each taste and did not reopen them until they had made the judgment. In the dark-adapted condition, the subjects adapted to the low light levels (red light of intensity $<1 \mathrm{~lx}$ ) for $15 \mathrm{~min}$ before beginning to taste, but tasted with their eyes open. The order of the three light conditions was randomized across subjects. No subject had previously participated in a psychology experiment.

\section{Results and Discussion}

Following Moskowitz (1971), magnitude estimates 
of perceived intensity ( $I$, the geometric mean of a subject's magnitude estimates for a condition) are related to molar concentration (C) by a power function. Thus, the relation between log magnitude estimate and $\log$ concentration should be linear, since $\log (\mathrm{I})=$ $\mathrm{a}+\mathrm{b} \log \mathrm{C}$, when $\mathrm{I}=\mathrm{aC}^{\mathrm{b}}$. Consequently, least squares regressions of $\log I$ on $\log C$ were performed, to facilitate comparisons between conditions. As expected, these analyses, which are summarized in Table 1, show that the relationships between concentration and perceived intensity are well described by power functions $\left(\mathrm{r}^{2}\right.$ values range from .87 to .99 , with a median value of .95). Based on Stevens' wellknown results (e.g., Stevens, 1974), these fits are as expected.

With the magnitude estimation paradigm, differences in performance are primarily differences in the rate of growth of sensation. Growth of sensation is represented by the exponent of the power functionin Table 1 , by the values of the slope, $b$, of the relation $\log \mathrm{ME}=\mathrm{a}+\mathrm{b} \log \mathrm{C}$. Hence, the comparison of performance in the three conditions reduces to the comparison of slopes. These values are given in the three leftmost columns of Table 1 for eyes-open, dark, and eyes-closed conditions, respectively.

The clear conclusion from this comparison is that sensation grows fastest for the eyes-open condition! Eight of the nine subjects show the largest slopes for eyes-open condition ( $p<.05$, by sign test). Sensations grow most slowly in the eyes-closed condition: slopes are least here for seven of the nine subjects $(p<.05$, by sign test). These results eliminate the notion that dark-adapted body state produces a heightened sensitivity to sour taste, at least when the taste is chemically induced. Also, the notion that eliminating visual stimulation would improve taste sensitivity through an attentional effect is rejected, since the eyes-closed condition produced the poorest performance. Rather, the present results suggest that concurrent visual stimulation increases taste sensitivity and that removing the visual input, even temporarily, decreases the rate of growth of sensation. On this view, the intermediate performance in the dark-adapted condition would be explained entirely as due to attentional factors: Visual input at levels (continuously) intermediate to those in the eyes-open and eyes-closed conditions has a correspondingly intermediate effect on attention. Thus, dark-adapted/eyes-closed performance would be still poorer than light-adapted/eyes-closed performance. This notion was tested in the second experiment.

Experiment 1 examined the speed with which sensation grows, using magnitude estimates of the perceived intensity of supraliminal levels of "sour" taste. It remained possible that dark-adapted body state enhanced sensitivity at threshold, but that other effects would dominate above threshold. Consequently, a second experiment was carried out, in which sensitivity to near-threshold levels of $\mathrm{CH}_{3} \mathrm{COOH}$ (concentrations between $9 \times 10^{-5} \mathrm{M}$ and $1 \times 10^{-4} \mathrm{M}$ ) were tested in a signal detection paradigm. If dark-adapted body state enhances sensitivity at threshold, we would expect sensitivity in the dark-adapted/eyes-closed condition to exceed that in the eyes-closed condition. However, to the extent that the effects are attentional and of the form seen in Experiment 1, we would expect sensitivity to be least in the dark-adapted/eyes-closed condition.

\section{EXPERIMENT 2}

\section{Method}

Subjects. Six introductory psychology students volunteered to taste without pay. The subjects tasted 120 test solutions during each of seven 60 -min-long sessions. No subject had previously participated in a psychology experiment.

Stimuli. During each session, the subjects were presented with a completely randomized sequence of target (acid) and distractor (distilled water) solutions, with a water rinse preceding each taste. Target solutions were acetic acid at a temperature of $23^{\circ} \mathrm{C}$ and at concentrations fixed between $9 \times 10^{-5}$ and $1 \times 10^{-4} \mathrm{M}$ for individual subjects. Distractor solutions were distilled water at $23^{\circ} \mathrm{C}$. All solutions were tested from .75 -oz paper portion cups, immediately after filling.

Procedure. During Session 1, each subject alternately tasted the

Table 1

Performance Summaries for the Nine Subjects of Experiment 1

\begin{tabular}{|c|c|c|c|c|c|c|c|c|c|}
\hline \multirow[b]{2}{*}{ Subject } & \multicolumn{3}{|c|}{ Slope } & \multicolumn{3}{|c|}{ Intercept } & \multicolumn{3}{|c|}{$\mathrm{r}^{2}$} \\
\hline & $\begin{array}{l}\text { Eyes } \\
\text { Open }\end{array}$ & $\begin{array}{c}\text { Dark } \\
\text { Adapted }\end{array}$ & $\begin{array}{c}\text { Eyes } \\
\text { Closed }\end{array}$ & $\begin{array}{l}\text { Eyes } \\
\text { Open }\end{array}$ & $\begin{array}{c}\text { Dark } \\
\text { Adapted }\end{array}$ & $\begin{array}{c}\text { Eyes } \\
\text { Closed }\end{array}$ & $\begin{array}{c}\text { Eyes } \\
\text { Open }\end{array}$ & $\begin{array}{c}\text { Dark } \\
\text { Adapted }\end{array}$ & $\begin{array}{c}\text { Eyes } \\
\text { Closed }\end{array}$ \\
\hline 1 & .51 & .37 & .31 & 1.67 & 1.62 & 1.58 & .89 & .95 & .98 \\
\hline 2 & .58 & .53 & .41 & 2.01 & 1.86 & 1.83 & .93 & .95 & .97 \\
\hline 3 & .53 & .48 & .46 & 1.91 & 1.61 & 1.66 & .96 & .96 & .94 \\
\hline 4 & .39 & .28 & .36 & 1.63 & 1.43 & 1.53 & .92 & $\begin{array}{l}.90 \\
.98\end{array}$ & $\begin{array}{l}.74 \\
.99\end{array}$ \\
\hline 5 & .56 & .52 & .51 & 1.61 & 1.60 & 1.60 & .92 & $\begin{array}{l}.80 \\
.87\end{array}$ & .92 \\
\hline 6 & .53 & .51 & .53 & 1.49 & 1.41 & 1.52 & .96 & .91 & .95 \\
\hline 7 & .52 & .51 & .47 & 1.55 & 1.59 & 1.55 & .94 & .93 & .94 \\
\hline 8 & .56 & .58 & .49 & 1.93 & 1.85 & 1.82 & .95 & .97 & .9 .7 \\
\hline 9 & .71 & .58 & .55 & 1.91 & 1.85 & 1.99 & .96 & .92 & .87 \\
\hline
\end{tabular}

Note-Entries are slopes (b), intercepts (a), and $r^{2}$ values for the least-squares regressions of log magnitude estimates on log molar concentration: $\log (M E)=a+b \log (C)$. 
(labeled) target (acetic acid) and distractor (distilled water) solutions for several minutes to become familiar with the target taste. Standard signal detection instructions were then given, with the subjects being told to indicate after each taste whether they thought acid or water had been presented and then to indicate whether they were certain or uncertain of the decision. The subjects were told that the numbers of acid and water solutions would be approximately equal, and were asked to attempt an even balance of acid certain, acid uncertain, water uncertain, and water certain decisions. The subjects were told that solutions would be presented in a randomized order, and they were warned against using sequential response strategies. No accuracy feedback was provided during the experiment.

Following an initial practice session, all subjects were tested twice under each of the dark-adapted, eyes-open, and eyes-closed conditions. In the dark-adapted condition, the subjects were instructed to close their eyes while tasting. Other aspects of the experiment were as described for Experiment 1 . The order of sessions was randomized across subjects.

\section{Results and Discussion}

To permit taste sensitivity to be measured independently of the influence of response biases (for example, of the tendency to respond "acid" vs. "water" or "certain" vs. "uncertain"), signal detection analyses were performed on the data. Viewing the various responses as indicating sensations which exceed a particular criterion allows ROC curves to be plotted (cf. MacNicol, 1972). Briefly, it is assumed that "acid certain" responses indicated sensations which exceed even the strictest criterion, and these responses were used to estimate the coordinates for the first (lower leftmost point) of the ROC curve. The coordinates for the second point are provided by the estimate of the probability of a sensation exceeding the next strongest criterion (acid uncertain). Thus, "acidcertain" and "acid-uncertain" responses are cumulated, and the corresponding probabilities are used to plot the second point on the ROC curve. Finally, "wateruncertain" responses are added to this total to locate the third point.

Once these coordinates have been determined, a simple robust measure of sensitivity is available as $\mathbf{A}^{\prime}$, the area under the ROC curve. $\mathbf{A}^{\prime}$ provides a measure of sensitivity which varies between .5 (chance) and 1 (perfect discrimination). $A^{\prime}$ measures for the ROC curves of Experiment 2 are presented in Table 2, as a means of comparing performance across conditions. It is clear from the table that the light-adapted conditions dominate the dark-adapted condition throughout. Thus, as in Experiment 1, the observed result directly contradicts the result claimed by Dobrjakova. Furthermore, the eyes-closed condition dominates the dark-adapted condition for five of the six subjects. Thus, it does not appear that taste sensitivity is merely unaffected by the dark-adapted body state. Rather, the dark-adapted body state actually decreases sensitivity.

The most parsimonious explanation for the results found here would seem to be based on the notions of arousal and/or attention. Briefly, it seems reason-
Table 2

A' Estimates for Experiment 2

\begin{tabular}{cccc}
\hline & \multicolumn{3}{c}{ Condition } \\
\cline { 2 - 4 } Subject & $\begin{array}{c}\text { Eyes } \\
\text { Open }\end{array}$ & $\begin{array}{c}\text { Dark } \\
\text { Adapted }\end{array}$ & $\begin{array}{c}\text { Eyes } \\
\text { Closed }\end{array}$ \\
\hline $\mathrm{W}$ & .776 & .722 & .775 \\
$\mathrm{G}$ & .560 & .538 & .546 \\
$\mathrm{P}$ & .682 & .555 & .612 \\
$\mathrm{~N}$ & .755 & .531 & .762 \\
$\mathrm{~K}$ & .699 & .671 & .551 \\
$\mathrm{H}$ & .620 & .503 & .742 \\
\hline
\end{tabular}

Note-Entries are $A^{\prime}$, the area under the ROC curve for each condition.

able to conclude that: (1) decreasing the level of ambient illumination decreases both sensitivity and the growth of sensation, concurrently with decrements in arousal level; (2) some sensitivity decrement is induced both when one closes the eyes and when one becomes adapted to low light levels; and (3) these effects are additive - closing the eyes, together with dark adaptation, will produce a larger performance decrement than will either in isolation. Still, this explanation does not apply universally: two of the subjects in Experiment 2 performed best in the eyes-closed condition. Since closing the eyes may thus enhance performance, some subjects may be able to overcome what would normally be performance decrements caused by the lower levels of visual stimulation, perhaps by selective attentional mechanisms.

\section{GENERAL DISCUSSION}

The present results clearly deny Dobrjakova's assertion that taste sensitivity increases when subjects have been dark-adapted. In Experiment 1, the growth of sensation was most rapid when concurrent visual stimulation was present. In Experiment 2, sensitivity was superior while light-adapted, both for eyes-open and for eyes-closed tasting.

While many find these results contrary to their intuitions, they are quite in keeping with the findings of studies on sensory interaction performed earlier in this century: The effects those investigations demonstrated are most easily termed "arousal." For example, in the 1930s, many European investigators demonstrated that continuous visual stimulation decreased auditory threshold (e.g., Child \& Wendt, 1938) and increased discriminability of tones on the basis of pitch or intensity (e.g., Hartmann, 1933). Similarly, Bornstein (1936) reported interactions between visual brightness and a host of nonvisual stimuli: sounds, tastes, smells, and ultraviolet (but not infrared) radiation of skin were found to increase the judged visual brightness of a stimulus. Thus, there is much support from work in other modalities for the results of Experiment 1.

The results reported here are confined to chemically 
induced tastes, the natural situation, while Dobrjakova's results were for electrically induced sour taste. Thus, the discrepancy may reflect an idiosyncratic result (since, as noted, Dobrjakova's result was never replicated); it may reflect differences between electrical and chemical taste; or it may reflect curious, and as yet undetected, interactions. What the present results do unambiguously demonstrate is that taste in the dark can be clearly inferior to taste in the light. Maybe that's why the "best" restaurants are dimly lit?

\section{REFERENCES}

BORNSTEIN. W. On the functional relations of the sense organs 10 one another and to the organism as a whole. Journal of General Psvchologv, 1936, 15, 117-131.

Bu.jas, Z. Electrical tastes. In L. Beidler (Ed.), Handbook of sensory physiology (Vol. 4). Chemical senses. (2) Taste. Berlin: Springer-Verlag, 1971.

CHII.D, I., \& WENDT, G. R. The temporal course of the influence of visual stimulation upon the auditory threshold. Journal of Experimental Psychologv, 1938, 23, 109-127.
DobrJakova, O. A. [Parallelism in the changes of electrical sensitivity in the organs of vision and taste under the conditions of optical and taste stimulation] (in Russian). Journal of Physiology of the USSR, 1939, 26, 192-199.

Hartmann, G. W. Changes in visual acuity through simultaneous stimulation of the other sense organs. Journal of Experimental Psychology, 1933, 16, 393-407.

MacNicol, D. A primer of signal detection theory. London: George Allen and Unwin, 1972.

MARKs, L. E. Sensory processes. New York: Academic Press, 1974.

Moskowitz. H. R. Ratio scales of acid sourness. Perception \& Psychophysics, 1971, 9, 371-374.

Nachman, M., \& Cole, L. P. Role of taste in specific hungers. In L. Beidler (Ed.), Handbook of sensory physiology (Vol. IV). Chemical senses. (2) Taste. Berlin: Springer-Verlag, 1971.

OzBaydar, $\mathrm{S}$. The effects of darkness and light on auditory sensitivity. British Journal of Psychology, 1961, 52, 285-291.

Stevens, S. S. Perceptual magnitude and its measurement. In E. C. Carterette \& M. P. Friedman (Eds.), Handbook of Perception (Vol. 2) Psychophysical judgment and measurement. New York: Academic Press, 1974.

(Received for publication April 7, 1980; revision accepted September 15, 1980.) 